\title{
"SIGNS FOR A PEOPLE WHO REASON": RELIGIOUS EXPERIENCE AND NATURAL THEOLOGY
}

\author{
AMBER L. GRIFFIOEN \\ UNIVERSITY OF KONSTANZ
}

\begin{abstract}
In this paper, I examine various philosophical approaches to religious experience and natural theology and look at some ways in which the former might be relevant for the latter. I argue that by thinking more about oft-overlooked or -underemphasized understandings of a) what might constitute religious experience and b) what functions natural theology might serve, we can begin to develop a more nuanced approach to natural theological appeals to religious experience - one that makes use of materially mediated religious experience to develop a natural theology more sensitive to the varieties of experience of lived religion "on the ground".
\end{abstract}

\section{INTRODUCTION}

In some respects, the relationship of religious experience and natural theology is somewhat well-trodden territory. Much philosophical ink has been spilled on both relata, and the scholarly treatments of each individual relatum have also often either explicitly or implicitly touched on questions relevant to the other. Still, little has been written recently on the genuine points of connection between these two subjects of inquiry, in part due to the immense diversity of ways in which each term has been used in the literature. ${ }^{1}$ Indeed, the way we choose to approach these concepts will have significant effects on the way we understand the relationship between them. In this essay, I hope to move the discussion forward by initially taking a few steps back. I thus begin by discussing a few issues regarding how 'religious experience' is to be understood, and I suggest a few new avenues for philosophical and theological

Notable exceptions include Wynn (2013), Sudduth (2009b), and, to some extent, McGrath (2008). 
exploration. I then look at a few ways in which the term 'natural theology' can be employed and explore the question of how we might characterize the aim of natural theology. This discussion is followed by an examination of three ways in which religious experience may be relevant for natural theology. Ultimately I argue that it would be fruitful for analytic philosophy of religion to further expand its focus to include the somewhat underemphasized category of materially mediated religious experience and to explore its relevance for the natural theological enterprise.

\section{WHAT IS RELIGIOUS EXPERIENCE?}

There are many scholarly debates relevant to delineating the assortment of phenomena characterized in various contexts as 'religious experience', only a few of which can be discussed in detail here. ${ }^{2}$ Most of these debates hinge on questions of what makes a religious experience religious, as opposed to some other kind of experience. Less commonly, questions arise regarding how best to understand the term 'experience' and what kinds of religious phenomena may fall under the experiential umbrella. In this section, I intend to briefly examine both questions, if only to point to the complexity of understanding what might be meant by the term 'religious experience'.

\section{What Makes an Experience Religious?}

One common and long-standing debate in the literature on religious experience is whether or not there is some common feature or set of fea-

\footnotetext{
2 For example, I will not be discussing whether or not 'religious experience' is a success term (i.e., whether an experience will only count as a religious experience if it is actually caused by God or some other "religious" entity). Although this idea is motivated by the common analogy between religious experience and perception (and by a common grammatical use of the term 'experience'), there are also worries about viewing religious experience as a factive notion (cf. Griffioen 2017). The reader who wishes to use 'religious experience' in a veridical sense may substitute 'purported religious experience' for 'religious experience' throughout. Further, I do not have space here to consider the relationships between religious, mystical, and spiritual experience. Since the debates surrounding mystical experience tend to mirror those regarding religious experience, and since many mystical experiences occur in religious contexts, I will use the terms more or less synonymously in this paper, and I will largely drop all discussion of spiritual experience. This is not to say there are not relevant distinctions to be drawn here, only to note that doing so might take us too far afield.
} 
tures shared by all religious experiences. Perennialists maintain that there is something common to the nature or phenomenology of religious experience - something unites all genuine cases of religious experience over space, time, and culture. ${ }^{3}$ Non-perennialists - often proponents of some form of constructivism or other - deny this. So, for example, in $\$ 4$ of The Christian Faith Friedrich Schleiermacher characterizes the essence of religion as containing a "feeling of absolute dependence" (Schleiermacher 1999: 12ff.). Similarly, Rudolf Otto insists that religious experience is, at its core, a nonconceptual, non-rational, ineffable experience of mysterium tremendum (cf. Otto 1958: 12). It is "a peculiar difference of quality in the mental attitude and emotional content of the religious life itself" (3), a "special way" of being "reflected in the mind in terms of feeling" that represents "the deepest and most fundamental element in all strong and sincerely felt religious emotion" (12). William Stace, on the other hand, distinguishes between "extrovertive" and "introvertive" mystical experiences of the unity of all things, both of which are taken to be universal (cf. Stace 1961: 79-86). Later scholars have spoken of so-called "pure conscious events" (cf., e.g., Forman 1997), in which the subject-object distinction is largely eliminated, and which they claim can be found across theistic and non-theistic traditions. The perennialist idea is thus that the "raw" mystical or religious experience is distinguishable from its interpretation (cf. Smart 1965), such that although figures in various traditions understand or relate their experiences under different descriptions, the underlying nature or quality of the experience is the same - and it is distinct from other kinds of experience.

However, the intuition that experiences are distinct from and prior to their interpretations might not be as plausible as one might think at first glance. Non-perennialists, especially those endorsing a so-called "constructivist" or "attributionalist" approach (e.g., Proudfoot 1985; Taves 2009), maintain that we cannot separate our experiences from the social, historical, linguistic, and conceptual frameworks that inform their interpretations. Instead, they claim, the cultures in which we are embedded and the concepts we inherit fundamentally underlie and shape the nature of our experience. In other words,

\footnotetext{
3 Many perennialists also hold that the purported commonality is what makes the designation of an experience as religious appropriate.
} 
experience and interpretation are inextricably intertwined. Thus, the nonperennialist denies the claim that individuals having religious experiences in different religious contexts are necessarily having the same sort of experience, allowing that, e.g., the religious experience of a $21^{\text {st }}$-century Christian in Western Europe might differ essentially from that of a $21^{\text {st }}$-century European Muslim or Buddhist, a $16^{\text {th }}$-century European Christian, or even a $21^{\text {st }}$-century Christian in West Africa. Likewise, two individuals who have visions of Jesus might have qualitatively different types of religious experience, depending, for instance, on whether one takes Jesus to be the Son of God or a non-divine prophet. Thus, whereas perennialists emphasize the similarity and generality of transcultural, transhistorical religious experiences, non-perennialists worry about the essentializing nature of such generalizing, focusing instead on the diversity and particularity of religious experiences as situationally embedded in place and time.

The view one adopts with respect to this debate regarding experience and interpretation has direct consequences for questions regarding religious experience's relationship to natural theology. Schleiermacher, for example, claims that the "feeling of absolute dependence [...] is therefore not an accidental element, or a thing which varies from person to person, but is a universal element of life; and the recognition of this fact entirely takes the place, for the system of doctrine, of all so-called proofs of the existence of God" (Schleiermacher 1999: 133-4). In this sense, a theory of religious experience could actually supplant traditional natural theological arguments - either as a new form of natural theological argument, or as the end of natural theology altogether. ${ }^{4}$ A slightly less radical claim is that the truth of perennialism could provide natural theologians with better justification for certain general theological claims, especially those concerning the existence of a higher reality. As Stephen Bush notes: "If perennialists are right that mystical experiences have a common core, then they can appeal to a wide variety of experiences from various traditions as rational justification for belief in the existence of what-

\footnotetext{
4 The latter might also be compatible with Plantinga's (1980) "Reformed objection" to natural theology, assuming that some proper basic beliefs could be (non-inferentially) grounded in or even prominently expressed through religious experience. However, as we shall see below, Plantinga's rejection (or sidelining) of natural theology rests on a particular understanding of the term 'natural theology', which we may not be forced to accept.
} 
ever reality they think the mystical experiences indicate" (Bush 2012: 102). This is not to say that a natural theologian who appeals to religious experience must embrace perennialism, as John Hick's work might show (cf., e.g., Hick 2006; 1984). Still, the perennialist may have an easier time of it when it comes to providing evidence for natural theological arguments from experience. Indeed, many such arguments appear to assume a kind of perennialism from the outset. Yet a focus on the radical plurality of religious experience may also have its benefits, as we shall see below.

\section{What Kinds of Experiences Count?}

Whatever position one ultimately endorses in the perennialist/non-perennialist debate, discussions of religious experience have - especially since the publication in 1902 of William James' The Varieties of Religious Experience typically focused on the experiences of particular individuals that stand out in their lives or that they themselves identify (or would identify, if prompted) as somehow special or unusual (cf. Taves 2009: 5). These experiences are usually temporally discrete and episodic, taking place at a particular time and having a clearly-defined beginning and end. Of course, James himself is careful to note that his investigation looks specifically at what he calls "religious geniuses" to bring the phenomena he is examining into clearer focus. He is not interested in the "ordinary religious believer, who follows the conventional observances of his country." Such religious experience James calls "secondhand" and a matter of "dull habit", due to its being "suggested", "communicated [...] by tradition", and "determined to fixed forms". Instead, he is interested in the kinds of "original experiences which were the pattern-setters" for such "second-hand" religion (James 2004: 19).

Further, although James may have played a large role in shaping the way scholars have approached religious experience, the emphasis on religious experience as largely individualistic, episodic, and life-changing goes at least as far back as $18^{\text {th }}$-century Lutheran pietism and was cemented in Western culture through such movements as English and European Romanticism, the Great Awakenings, and American Transcendentalism. Indeed, "Conversion" and "rebirth" narratives dominate much Western (especially Protestant) religious discourse. Moreover, many mystical and mystagogical traditions (which James also discusses) imply that the end of the "mystical path" 
involves some sort of experiential union with God, thus also appearing to privilege the special nature of certain kinds of individual experiences. So, for many of us, this kind of "setting apart" of religious from ordinary experience might seem quite natural. Yet many - even most - people have never undergone drastic experiences of the kind described by James and likely never will. Still, it is not as though God is completely absent from their lives, nor is religious experience.

Even in Evangelical Christian traditions, with all their emphasis on dramatic and sudden religious experience, experience of God is often also sought in the everyday, as Tanya Luhrmann's close anthropological study of California "Vineyard Christian" communities attests. These believers, Luhrmann writes, have "an intense desire to experience personally a God who is as present now as when Christ walked among his followers in Galilee" (Luhrmann 2012: 13), and they pursue practices by which they can come to hear God's voice speaking to them as they go about their ordinary lives. Through engaging in playful-yet-sincere exercises - including activities like "chatting with God", "singing with God in the shower", or even planning a regular "date night" with God (80) - the Vineyard Christians strive to make hearing God's voice or feeling God's presence a regular and natural feature of their everyday experience. That such a skill must be developed also highlights the limitations of viewing religious experience as fundamentally discrete or episodic. In the case of the Vineyard Christians, even where adherents might point to specific events in which "the supernatural breaks through into the everyday" (56) and delivers a specific message, learning to recognize certain patterns (57) and coming to progressively re-orient one's inner affective dispositions (109) are crucial for being able to hear that message and ultimately form constituent parts of one's religious experience. "Hearing God's voice is a complex process," Luhrmann writes (60), one that itself arises through experience. Here, the relevant understanding of 'experience' is the same as that involved in becoming an "experienced wine-taster" or a "learned piano player". There is a diachronic, progressive aspect to religious experience understood in this way, and to focus solely on the particular, episodic "happenings" that arise out of such experience is to limit our investigation into the ways that religious experience may be relevant for natural theology, as I will discuss in more detail below. 
In a similar vein, the various forms of religious practice communicated through tradition and cemented in culture - James' habitual, "second-hand" religion - both ground and shape the structure of the general experience of the ordinary religious faithful. Indeed, the mundane, habitual, embodied practices of religious adherents and the feelings and sensations that accompany them might be central to understanding religious experience. Moreover, such experience is not solely individualistic. Much of it represents a kind of experience that is intersubjective, communal, and otherwise shared. ${ }^{5}$ Certainly, it relies on religious experience's being "communicated" and "determined to fixed forms", as James put it, but such social-historical communication and cultural determination of form is what allows communities to mutually experience and identify the objects set apart in the religious tradition to which they belong. Such forms are also dynamic and shift as communities imaginatively (re-)negotiate the boundaries of the religious concepts and objects that frame the nature of their shared experience.

There are more categories here worth of further discussion. For example, much of the focus on religious experience in the literature takes it to be largely a mental occurrence (e.g., Swinburne 2004: 293). Yet the body also plays a significant role in both discrete and diachronic religious experience of both special and mundane kinds (cf. Coakley 2009). Not only do bodily practices sometimes effect or even constitute religious experiences, mental religious experiences elicit strong bodily responses in the experiencer. Indeed, for some cases of religious experience we might think the body plays a more significant role than any particular mental attitude. Further, there is a question of whether only "positive" experiences should be under discussion in our treatments of religious experience. First, not all religious expe-

\footnotetext{
5 One might admit that just as there is a sense in which certain groups may be said to "share" a culture or history, groups may also be characterized by a collectively-shared experience. Similarly, just as it seems plausible to make reference to collective beliefs, intentions, and actions, it does not seem out of place to talk about discrete collective experiences. We might even think that, in some cases, collective religious experience might display properties not reducible to the aggregate of those of its individual experiential "parts". In any case, little philosophical ink has, so far as I know, been spilled on either notion of "shared experience". Still, notable mentions of the former may be found in various discussions of identity politics (cf., e.g., Alcoff 2005: 278), and a brief examination of compassion moving in the direction of the latter can be found in Cates (1997: 140ff).
} 
riences and emotions are positively valenced. Experiences of the demonic or those experiences of the Divine that elicit extreme fear, sadness, or even anger might plausibly count as religious experiences. Second, on a slightly different understanding of the positive-negative distinction, one might wonder whether religious experience must always involve the presence of some object, or whether experiences of transcendence, absence, or divine hiddenness might also be relevant subjects for discussions of religious experience. ${ }^{6}$

Given the above considerations, it is clear that the relevance of religious experience for natural theology has much to do with how 'religious experience' is understood. However, there is also substantial ambiguity in the term 'natural theology', and an examination of the various ways it has been used in the literature will likewise assist in our examination of how it is that religious experience might be significant for natural theology and vice versa.

\section{WHAT IS NATURAL THEOLOGY?}

\section{Understandings of Natural Theology}

There are many competing accounts of 'natural theology', both implicit and explicit, in the literature. In the Abrahamic traditions, the realm of natural theology has historically been delineated by contrasting it with "revealed" theology. Of course, the term 'revelation' itself is rather vague. Not only does it refer to the content of what is communicated; it is also used to denote the act of God's communicating that information, as well as the medium by which it is communicated (cf. Griffioen 2017). Thus, the distinction between natural theology and revealed theology depends largely on what sense of revelation is under discussion. A broad understanding of revealed theology claims that it contains those truths revealed to human beings via any sort of divine activity or theophany, including God's general creative and sustaining activity. A narrower and more common understanding reserves for revealed theology only those propositions purportedly conveyed via a special divine act of

For a discussion of experiences of absence, see Farennikova (2013). See also Coakley (2009) for a discussion of the religious significance of so-called "apophatic" experiences and Turner (2005) for a treatment of religious experience as absence and its relevance for natural theology. 
communication to particular persons at particular times - truths generally passed down in the holy texts or oral tradition of a particular religious tradition. On the latter understanding, then, natural theology contains those propositions accessible to human beings without recourse to Scripture or the testimony of the persons and traditions to and via which the propositions of revealed theology were purportedly communicated. Of course, on both the broad and narrow understandings, revealed theology may contain propositions that also fall under the purview of natural theology, though presumably the former additionally includes propositions not found in the latter. ${ }^{7}$

Yet even if we accept this rough characterization of natural theology, it is merely a way of getting at what natural theology is by talking about what it is not. When it comes to positively characterizing natural theology, there are at least two different general routes philosophers and theologians have adopted. The first places emphasis on method: Natural theology, they say, avails itself of discursive rational argumentation to arrive at theological conclusions. Yet even here, there are questions regarding what kinds of argumentation are acceptable: First, one might claim that what makes natural theology "natural" is its appeal to empirical facts about the natural world. Such approaches are likely to exclude or downplay a priori arguments like the Ontological Argument - an argument which some might take as a paradigm case of natural theological argumentation. Indeed, depending on how empirically-oriented such approaches become, they might even exclude certain forms of the kalam cosmological argument, whose premise that the universe has a beginning might not be "empirically robust" enough to pass muster. One might further ask whether appeals to pragmatic as well as theoretical reasoning could (or should) fall under the conceptual umbrella of natural theology.

A second approach to natural theology views it as involving theological knowledge or understanding arrived at via the use of one's natural cognitive

It is less commonly discussed whether natural theology could contain propositions not found in revealed theology, yet this, too, seems conceivable, especially on the narrow understanding of the latter, since there could be truths about God knowable through reason that have, for providential reasons, not (yet) been revealed through any special divine act of communication. Further, many propositions of Classical Theism (e.g., 'God is impassible' or 'God is omnibenevolent') might not be explicitly (or even implicitly) stated in Scripture, such that natural theology might be said to go beyond revealed theology by filling in important hermeneutical "gaps" in the latter. 
faculties. Thus, the "natural" aspect of natural theology comes not primarily through a focus on natural features of the universe but from the implementation of certain "natural" human capacities. Of course, this approach often overlaps with the methodological view, since engagement in rational argumentation requires the exercise of human reason. ${ }^{8}$ Yet the faculty-centered approach to natural theology could also be broadened to include other capacities and ways of coming to know things, depending on what kinds of faculties one takes to constitute the "natural" ones. For example, if we think that emotional attitudes can reliably yield cognitive information, then theological truths arrived at via one's affective capacities might also be candidates for inclusion in natural theology. Further, the restriction of the "natural" to physical capacities might also be called into question. If it turns out God has universally endowed all human creatures with a sensus divinitatis or other "spiritual senses", where such senses may be said to belong properly to human beings, it might not seem so far-fetched to call such faculties "natural", even if they are not physically observable.

The approaches to natural theology laid out thus far tend to be intertwined (and thus sometimes run together in the literature). As with the term 'revelation', it is not always clear whether 'natural theology' refers primarily to a particular propositional content, a particular method or set of methods, or the medium or faculty employed. Usually it is some combination of these three. Thus, a very restricted understanding of natural theology might claim that natural theology is the set of true propositions about God which may be arrived at through the implementation of sound theoretical reasoning in the form of demonstrative argumentation, whereas a very wide understanding of natural theology might claim that it includes any and all cognizings of Ultimate Reality arrived at via the exercise of one's natural faculties without

\footnotetext{
8 The website of the prestigious Gifford Lectures, for example, merges all of the above understandings of natural theology: "Traditionally natural theology is the term used for the attempt to prove the existence of God and divine purpose through observation of nature and the use of human reason. [...] Natural theology is the part of theology that does not depend on revelation" (http://www.giffordlectures.org/overview/natural-theology, my emphasis). Sudduth (2009b) likewise defines natural theology as "rational arguments for the existence and attributes of God" but relates it essentially to "truths about God that may be known by the light of natural reason" and "natural knowledge of God" (214-15).
} 
recourse to Scripture or testimony. And each of these options may be modified to include/exclude various considerations of the kind discussed above.

A final way we might understand natural theology departs in some ways from the above approaches. This is the approach that takes natural theology to represent something like a theology of nature (cf., e.g., Pannenberg 1993; Hendry 1980). Ian G. Barbour (2009) describes such a view as "proposing ways in which a God who is accepted on other [non-scientific] grounds [...] might be reconceived as acting in nature" (34), whereas Azizan Baharuddin (2000) characterizes it as "a set of beliefs about God's relationship to the natural world" (614). Thus, theology-of-nature approaches do not reason from nature or natural faculties to the Divine but rather move from a theory of the Divine to conclusions about nature and the Divine's relation to it. Although both Barbour and Baharuddin distinguish theologies of nature from natural theology, it is worth keeping in mind that the two concepts are closely related and might have significant overlap - especially on certain understandings of the function or aim of natural theology.

\section{What is the Aim of Natural Theology?}

Ultimately, however, one might maintain that natural theology is as natural theology does. But what exactly does it do? What is it supposed to do? Here, there are various possibilities. One obvious answer is that natural theology aims at arriving at particular truths about God and the Divine - or, from the perspective of human inquiry, at knowledge. But this by itself might not be particularly helpful. For example, on the assumption that the most important theological truths are, in fact, reliably revealed in some particular religion, it might seem unnecessary to resort to natural theology to come to know these truths. Moreover, those engaged in natural theology seldom arrive at new or previously "undiscovered" theological truths. It is thus perhaps more productive to look at the dialectical function of natural theology. ${ }^{9}$ Natural theology has been used as an apologetic tool to defend certain theological doctrines

De Cruz \& De Smedt (2015) provide an overview of the dialectical function of natural theology in the first chapter of their Natural History of Natural Theology. See also Sudduth (2009b) for a comprehensive discussion of the various functions of natural theology in the history of Protestant thought. 
against criticism, as a polemical device to attack competing theological positions, and as a persuasive device to convince skeptics and doubters.

In the life of an individual believer or a particular religious faith, natural theology can also play a clarificatory role aimed at more carefully elucidating certain Scriptural concepts, or it may serve a reconciliatory function where there appear to be conflicts between revelation and reason. In such cases, natural theology may serve to provide one with greater understanding of what one already believes. It can be a way in which, to channel Anselm, fides can pursue intellectum. ${ }^{10}$ Yet the function of natural theology need not be purely epistemological or even cognitive: It may be a means by which one could engender love or other relevant affective attitudes, since one might wonder whether or not one could truly love something one cannot - at least to some relevant extent - understand. In this vein, Alister McGrath (2008), claims that natural theology is about "resonance, not proof" (15): "[N]atural theology does more than attempt to make intellectual sense of our experience of nature, as if it were limited to the enhancement of a rationalist account of reality. It enables a deepened appreciation of nature at the imaginative and aesthetic level, and also raises questions about how the 'good life' can be undertaken within its bounds" (18). So perhaps natural theology can serve an affective, aesthetic, or moral function as well. It might even be used as a form of prayer or worship in certain contexts, one which itself might elicit or constitute certain kinds of religious experiences. However, in what follows I will look more closely at the ways in which religious experience might provide material for natural theology. It is to a discussion of this that I now turn.

\section{THE RELATIONSHIP OF RELIGIOUS EXPERIENCE TO NATURAL THEOLOGY}

As we have seen in Parts II and III, the various understandings of both religious experience and natural theology make the task of showing the significance of the former for the latter a rather daunting one. In Part IV I wish to discuss three ways in which religious experience might be argued to be

10 For a detailed discussion of the various intended functions of Anselm's Proslogion, from reflection to persuasion, see Part I of Visser and Williams (2009). 
relevant to the enterprise of natural theology that rest on differing (though not always incompatible) approaches to these terms.

\section{Religious Experience \& Natural Theology I: Experi- ence as Non-Inferential Grounds for Knowledge}

I begin with a kind of appeal to religious experience that is often claimed to be independent of - and perhaps even at odds with - the natural theological enterprise. This is the claim that certain kinds of religious experience can provide immediate, non-inferential grounds for religious belief - belief which, if true, and if produced by a reliable mechanism, could count as knowledge. This kind of view has been endorsed most prominently by proponents of Reformed epistemology and often draws an analogy between religious experience and sense perception. William Alston (1993), for example, uses the term mystical perception to refer to cases in which subjects report "an experiential awareness of God," where "the awareness is direct" and "the awareness is reported to be of God" (14). Such experiences, Alston claims, may immediately and non-inferentially give rise to what he calls "M-beliefs", or "beliefs to the effect that God is doing something currently vis-a-vis the subject - comforting, strengthening, guiding, communicating a message, sustaining the subject in being - or to the effect that God has some (allegedly) perceivable property - goodness, power, lovingness" (1). A similar view is that put forward by Alvin Plantinga in his discussion of properly basic beliefs, which, he claims, may also arise immediately and non-inferentially from various forms of religious experience (cf. Plantinga 2000). Although Alston and Plantinga allow that there may be various forms of religious experience that occasion religious belief, both scholars focus most closely on the kinds of experience that look analogous to sense perception - at least insofar as, like perception, the relevant religious beliefs to which they give rise do not appear to be inferences drawn from evidence or the conclusions of some rational argument.

For this reason, both Alston and Plantinga contrast their views with what they take to be the natural theological enterprise. Yet their understanding of natural theology is centered on the methodological approach discussed above, on which natural theology proceeds discursively and inferentially by means of discursive argument or theoretical proof (cf. Plantinga 2000: 175; 
Alston 1993: 289). At the same time, although Alston notes that the kinds of experiences he is considering are "non-sensory" in the sense of not being mediated by sensory perception (cf. Alston 1993: 5), and although Plantinga is willing to accept experiences of both a mediated and non-mediated kind as grounds for basic religious beliefs (cf. Plantinga 2000: 182ff.), in both cases it seems to be that there is some faculty, capacity, or set of "skills" by which the relevant forms of belief-grounding religious experiences are possible in human beings. Plantinga's recourse to the sensus divinitatis makes this claim explicit. ${ }^{11}$ Indeed, he thinks that experientially grounded beliefs about God represent a kind of "natural knowledge". Thus he writes: "[T]his natural knowledge of God is not arrived at by inference or argument (for example, the famous theistic proofs of natural theology) but in a much more immediate way. The deliverances of the sensus divinitatis are not quick and sotto voce inferences from the circumstances that trigger its operation. [...] They are occasioned by the circumstances [...] not conclusions from them" (175). This "natural knowledge" is contrasted with the "non-natural" belief-producing process instigated by the Holy Spirit. The latter, he claims, is "not part of our original noetic equipment", whereas the former is "part of our original epistemic endowment" (Plantinga 2000: 180). In this sense, then, although Plantinga is keen to distinguish his project from that of natural theology, it is not incompatible with natural theology understood as a way of arriving at theological truths via the exercise of one's natural capacities (even if this might require the assistance of grace). Moreover, even though Plantinga himself raises some (historical, Reformed) objections to the methodological account of natural theology - namely that belief based solely on argument leads to a faith that is "unstable and wavering" (Plantinga 1980:53) - his own view, as Michael Sudduth points out, "is properly speaking a denial of certain strong forms of theistic evidentialism, not natural theology" (Sudduth 2009a: 44). The proper basicality thesis ultimately says that "some theistic beliefs can

\footnotetext{
11 Alston does speak of "perceptual skills" (91) and "spiritual discernment" (253), though these abilities have more to do with identifying or recognizing the object of awareness (as well as discerning forms of "true spirituality") than with creating the conditions for the awareness itself. Still, if the analogy between sense perception and mystical perception is to be a strong one, it would stand to reason that some faculty or capacity might need to be postulated to make sense of how non-sensory awarenesses of God can arise in the first place.
} 
have some (perhaps highly exalted) positive epistemic status for some people under certain conditions in the absence of [methodological] natural theology" (44). Yet this leaves room for the possibility that natural theology could take other forms or perform alternative functions like those we mentioned above and that religious experience might have some role to play in natural theology understood in this way.

Of course, even if we admit that natural theology understood on the faculty-approach might be open to epistemologists of the Reformed persuasion who insist upon the reasonableness of non-inferentially grounded religious beliefs on the basis of certain kinds of religious experience, it is unlikely that either said Reformed epistemologists or dogmatically-entrenched methodological natural theologians (especially of the evidentialist persuasion) will be particularly happy with this characterization. Indeed, allowing natural theology to include religious beliefs formed on the basis of any natural faculty whatsoever might threaten to blur the distinction between revealed and natural theology, at least insofar as one takes much of revealed theology to stem from religious experiences of just the kind Alston and Plantinga are purporting to describe. ${ }^{12}$ And this may be an unwelcome result to those for whom the distinction has theological significance.

\section{Religious Experience \& Natural Theology II: Experience as Evidence}

A more common way in which religious experience has been employed for natural theological ends takes the form of various arguments from experience, in which the fact that people have religious experiences is taken to be evidence for the existence of God. Here, the focus is less on the faculty by which such experiences arise and more on the evidential force of people's having had certain kinds of experiences for arguments concerning God's existence and attributes. One of the most prominent arguments adopting such an approach is Swinburne's "argument from religious experience" in The Existence of God. Swinburne here understands 'religious experience' as "an experience that seems (epistemically) to the subject to be an experience of God (either of [God's] just being there, or of [God] saying or bringing about something) or of some other supernatural thing" (Swinburne 2004: 295). While aware

\footnotetext{
12 It is, of course, unclear that special revelation has, in fact, usually taken this form.
} 
that his definition rules out many other kind of purported religious experiences, including some of those we have discussed above, Swinburne notes that "only religious experiences of the kind that my definition picks out have apparent evidential value in pointing towards the existence of God, and that is why I am concerned with them alone" (295-6, Fn. 2). He delineates five relevant kinds of religious experience, two of which involve taking a public object "religiously" (a kind of "seeing-as") and three involving private subjective experiences of objects unavailable to other subjects at the time (298-301). Pointing to the "millions of human beings down the centuries" who have had religious experiences of these kinds, and noting that "for many people life is one vast religious experience," Swinburne appeals to the since widelydiscussed Principles of Credulity (303ff.) and Testimony (322ff.) to argue that the fact of widespread religious experience can provide us with (defeasible) evidence for the existence of God.

Arguments of this kind look much more recognizable as natural theology because they involve inferential, argumentative reasoning from premises centered on the fact that people have religious experiences of certain kinds to theological claims about the existence of God. Similar appeals to religious experience could also serve to bolster further natural theological arguments about the attributes and nature of God, as well as various other theological doctrines (cf. Sudduth 2009b: 224-5). Of course, appeals to religious experience in natural theological argumentation have certain limitations. First, natural theological arguments from religious experience might only be able to serve particular (epistemological) functions. Certainly such arguments may be used in apologetic and polemical contexts, and they may serve clarificatory or confirmatory purposes, on the assumption that appeals to religious experience claiming that God is such-and-such can extend or solidify our beliefs about what God is really like (or how God prefers to reveal Godself to human beings). Yet it is unlikely that they can contribute to understanding in the sense of fides quarens intellectum as discussed above. While an individual's own religious experience may do this, arguments from religious experience are unlikely to do so. It is still possible that the argument may make someone more receptive to viewing their experiences of nature or other objects as divinely inspired, so perhaps it could "open one up imaginatively" to particular conceptions of God, but it could also have the opposite effect: 
For someone who has yet to experience God, the fact that others appear to interact personally with God while God remains hidden from oneself could lead to resentment or even skepticism.

This leads to another question regarding what kinds of experiences are under discussion in these arguments. On the one hand, an argument based on somewhat more perennialist understandings of religious experience might claim that the fact that people have religious experiences of a certain qualitative kind - experiences with particular phenomenal features - makes the hypothesis that, e.g., God exists more probable than competing hypotheses, or raises the probability that there is an afterlife, and so on. On the other hand, the claim might be that it is the content of the experiences that is most relevant to natural theology, such that the fact that people have experiences as of God (be they mediated or not, perceptual or not, episodic or not) is what lends evidential support to such hypotheses. ${ }^{13}$ Of course, in lived experience the two are not usually neatly separable. Still, being sensitive to this conceptual distinction may be important for the natural theological enterprise. Further, the fact that reports of religious experience vary widely and (at least appear to be) radically diverse may lend itself just as well to natural theological arguments against the existence of any particular God, especially if one has doubts about phenomenal perennialism. And given the fact that those who have religious experiences understood in terms of content "typically have a prior belief in God or extensive exposure to a theistic religion," one might even think that this "is just what one would expect on naturalism, while it is surprising on theism” (Draper 2002: 205).

\footnotetext{
13 Cp. Alston (1993) on this point: "Nevertheless, we can group phenomenally diverse experiences together $[\ldots]$ in terms of the content of beliefs to which they give rise: beliefs about perceivable features and activities of God. This puts us in a position to form the concept of a single doxastic practice, the inputs of which are experiential, and the outputs of which are M-beliefs" (186, my emphasis). However, in contrast to constructivists like Proudfoot, Alston wants to adopt a theory of perception "that gives us a chance to find common phenomenal features of mystical perception across cultures" (187). “To be sure," he notes, "to discern a commonality in phenomenal content, we must be able to distinguish this from the conceptualization to which it is subjected. But [...] on my view, the fact of X's appearing to $S$ as $\varphi$ is, in principle, independent of any conceptualization or judgment, independent of S's taking X to be $\varphi$ or believing or judging $\mathrm{X}$ to be $\varphi$, or even thinking of X as $\varphi$ " (186).
} 
It is also worth mentioning that the focus in analytic religious epistemology in general is yet again on religious experience understood as a kind of direct, discrete, "special" kind of experience. And while this certainly doesn't speak against including such experiences as relevant to natural theology, one might think that the rather myopic focus on religious epistemology has in part driven philosophical discussions of the metaphysics of religious experience. That is, in their desire to locate types of religious experience that lend themselves well to natural theological argument, analytic philosophers of religion have shaped the arena of discourse concerning the nature of religious experience, focusing almost exclusively on a very restricted set of experiences. ${ }^{14}$ Certainly, Alston, Plantinga, and Swinburne all make room for experience understood in a broader sense, but the role that mundane, diachronic, and collective religious experience plays in the religious life is minimized in favor of dramatic, episodic, quasi-perceptual religious experiences. Yet these latter kinds of religious experience are, in the grand scheme of things, relatively rare. Indeed, many versions of the so-called "argument from divine hiddenness" take as their starting point the relative absence of such religious experience, even amongst those who would welcome such experiences. As Michael Rea (2009) puts it: " $[\mathrm{M}]$ any people — believers and unbelievers alike - have never had an experience that seems to them to be a direct experience or awareness of the love or presence of God; and those who do have such experiences have them rarely" (76).

In any case, a natural theology that focuses solely on religious experiences of the special, perceptual kind fails to do justice to many significant experiential aspects of lived religion and might thereby unnecessarily restrict the force of its arguments. Thus, in the interest of natural theology, I suggest philosophers shift their focus to another much-overlooked aspect of many religious experiences that may be conducive to the expansion and exercise of the positive natural theological enterprise. In the next section, I turn to an examination of an oft-ignored aspect of many religious experiences, attention to which might give natural theologians a further direction in which to take their arguments from experience. This is the category of materially mediated religious experience.

14 See also Coakley's (2009) discussion of the limits of Swinburne's view (289ff.). 


\section{Religious Experience \& Natural Theology III: Toward a More Natural Experience of the Natural World}

The idea that religious experience is often - perhaps even usually mediated was brought most prominently to attention by George Mavrodes (1970) and has been taken up again more recently by C. Stephan Evans (2011; 2010; 1985), Mark Wynn (2013; 2012; 2009), and David Brown (2004), among others. Now, to be sure, there is an obvious (though not entirely insignificant) sense in which most or all religious experience might be mediated: First, we are embodied creatures, and we might think that all of our experience is thus in some way necessarily mediated by the body. Second, theistic experience, or the experience of God, is often implicitly taken to constitute a form of divine expression, self-revealing, or other means of communication. Yet communication necessarily requires a medium by which the relevant information is communicated. (Certainly, it is at least conceivable that God could directly "infuse" someone's mind with particular information, such that the causal process circumvents the bodily senses, but even this kind of "direct" awareness of God would be produced by the medium of infusion. ${ }^{15}$ ) Indeed, although the philosophers we have discussed thus far will often speak of religious experience as "direct" and "immediate", they do not appear to mean to be speaking of wholly unmediated experience. ${ }^{16}$ The "directness" feature of religious experience appears to have more to do with the fact that the object of experience is not perceived through the perception of any other object (cf. Alston 1993: 21). The "immediacy" aspect, on the other hand, seems to have more to do with the fact that one's beliefs about the object of the experience are claimed to arise non-inferentially. "Immediacy" thus appears to refer to the (psycho-)logical proximity of experience and belief, not to a lack of mediation. In any case, it appears possible to have direct, immediate experiences of a mediated kind (cf. Evans 1985: 87). Still, a more interesting kind of mediated experience for our purposes here is that of materially mediated

\footnotetext{
15 Cp. medieval discussions of angelic knowledge as infused (e.g., Goris 2012).

16 Alston himself says as much, when he notes that in "direct perception" (including direct perception of God), one "is aware of X through a state of consciousness that is distinguishable from X, and can be made an object of absolutely immediate awareness, but is not perceived". This "mediated immediacy" is distinguished from "absolute immediacy" and "mediate perception" (Alston 1993: 21-22).
} 
religious experience. This kind of experience is certainly not foreign to religious contexts. In fact, given the wide variety of forms such experience may take, it likely represents the most common kind of religious experience. It is this kind of experience I wish to explore more thoroughly in the remainder of this paper.

The notion of nature as providing "signs" of God and God's activity is prominent in the Abrahamic traditions. "The heavens are telling the glory of God", Psalm 19:1 (NRSV) declares, "and the firmament proclaims [God's] handiwork". Likewise, Surah 45 of Quran states:

"Indeed, within the heavens and earth are signs for the believers. [...] And [in] the alternation of night and day and [in] what Allah sends down from the sky of provision and gives life thereby to the earth after its lifelessness and [in Allah's] directing of the winds are signs for a people who reason. [...] And [Allah] has subjected to you whatever is in the heavens and whatever is on the earth - all from [Allah]. Indeed in that are signs for a people who give thought" (Sahih International Translation, my emphasis).

Similarly, an extra-Quranic hadith qudsi quoted in many Sufi mystical texts has God proclaiming: "I was a hidden treasure, I desired to be known, I created creation that I might be known". ${ }^{17}$ Seyyed Hossein Nasr further elaborates on this idea of creation as containing "signs" of the Divine:

[I]n the Quran both the phenomena of nature and the verses of the Quran are called $\bar{a} y \bar{a} t$, or symbols and signs, each conveying a meaning beyond itself. Every a yah, besides its outward meaning, has a symbolic and inward significance. Every cosmic phenomenon is both a fact and a symbol of a noumenon $[\ldots]$ The universe is constituted of theophanies; the cosmos is a set of symbols to be contemplated and a means to reach the Symbolized, a book to be read and understood in both its outward and inward meanings. (Nasr 2007: 46-47)

In the idea of God as both "hidden" and "manifest" in the phenomena of nature, we see a few ways in which a materially mediated religious experience of nature and the enterprise of natural theology may be related. First, the experience of nature may provide one with "natural signs" of God's existence, attributes, and creative activity, which are immediately recognizable to those who "use reason" or "give thought". Or the features of nature we

17 Quoted in Baharuddin (2000), 616. 
experience may enter into inferential arguments of a natural theological kind. Evans $(2011 ; 2010)$, too, has pointed out the ways in which our experiences of nature could - both inferentially and non-inferentially - serve as grounds for religious beliefs. He cites the case of one's experiencing the intricacy of a flower:

Some people might well infer God's reality from [certain properties the flower has], by way of [...] cosmological or teleological arguments for God's existence. [...] However, [...] spiritually seasoned observers of the world might experience God through the flower without any kind of inference. Such persons, we might say, are able to see the world as God's handiwork; they are able to 'read' what some theologians have called the 'book of nature,' a manifestation or revelation from God distinct from those particular events and experiences that are inscribed in inspired, revealed writings [...]. (Evans 2011: 44).

Thus one may take the "signs" of nature given in experience as a starting point for discursive, rational argumentation, or one may simply come to "see" the truth of certain religious propositions by employing one's natural faculties.

Of course, although such appeals to religious experience may serve dialectical purposes, the experiences themselves may further function to express, strengthen, or renew one's faith through the implementation of our (most natural) capacities. They may provide one with a theology of nature that, as al-Ghazāli proposed, contributes both speculatively to the elucidation or understanding of certain religious doctrines and affectively to the all-encompassing love of God through God's "findableness" in nature (cf. Baharuddin 2000: 617, 631). And although experiences of nature are often individual and episodic in nature, for the seasoned religious believer - one who sees through a religious "lens", as it were - such religious experience may not be sudden, dramatic, or otherwise "special" but may be experienced in nearly everything one encounters. That is, such experiences may also be commonplace and mundane, but this does not speak against their usefulness in natural theological contexts. Finally, these and similar experiences may be positively or negatively valenced and could even include certain "apophatic" experiences, in which one becomes aware through the experience that the Divine wholly transcends the objects of one's experience (cp. Yadav 2016). 
Other forms of materially mediated experience are relevant here, too. Experiences of, e.g., sacred space or music may take a somewhat different form than religious experiences of natural signs. As Mark Wynn writes:

[Such experience can be] a way of cognizing the meaning which attaches to a localized material context, and of cognizing thereby the meaning which attaches to a more broadly defined cosmological or metaphysical context. It is, we could say, a matter of learning how to assign an appropriate significance to individual things in their material context, rather than a matter of coming to apprehend a further and rather special individual thing. (Wynn 2013: 333)

Wynn further notes that such forms of experience may be especially relevant for natural theology insofar as they invite "a certain conception of God, namely, as an overarching meaning, rather than as a supernatural 'object', and also a correlative epistemology, one which gives due acknowledgement to the sense-making capacities of the human body and of affective responses in particular" (Wynn 2013: 334). Moreover, these kinds of experience, as well as the bodily experiences of religious narrative expressed through ritual and liturgy, may move the discourse on religious experience to forms of collective and temporally extended experience - to the socio-historical, intersubjectively-informed experience of the faithful as a whole - as opposed to merely focusing on the discrete and largely esoteric experiences of relatively few individuals. Such experiences are more widespread (more "perennial", in one sense), and they reflect more fully the lived, interpreted experience of religion "on the ground". This is a promising direction for a natural theology making appeal to religious experience - one which has the potential to move the discourse in productive directions. First, it makes room for the role of the body in religious experience. Second, it may provide new and exciting ways to counter arguments from divine hiddenness. ${ }^{18}$ Finally, it creates space for natural theology to engage with a wide range of religious cultures and experiential traditions, opening up space for renewed and engaged interreligious discourse - especially, perhaps, on matters of special global and

\footnotetext{
18 See, for example, Michael Rea's (2009) answer to the aforementioned problem of the absence of religious experience in hiddenness arguments by pointing to "the possibility of mediated experiences of the presence of God through media that are themselves widely and readily accessible" (88).
} 
environmental concern. By widening (and deepening) our understanding of religious experience, then, we may perhaps employ the tools of methodological natural theology to arrive at an evidentially-sensitive, experientiallybased theology of nature that can inform concerted, cooperative action on issues that have far too long been ignored or combatively resisted by certain religious factions. ${ }^{19}$

\section{BIBLIOGRAPHY}

Alcoff, L. M. 2005. Visible Identities. Race, Gender, and the Self. Oxford: Oxford University Press.

Alston, William P. 1993. Perceiving God. The Epistemology of Religious Experience. Ithaca: Cornell University Press.

Baharuddin, Azizan. 2000. The Significance of Dūfi-Empirical Principles in the Natural Theology and Discourse on Science in Islam. Islamic Studies 39 (4): 613-632.

Brown, David. 2004. God and Enchantment of Place. Reclaiming Human Experience. Oxford: Oxford University Press.

Bush, Stephen S. 2012. Concepts and Religious Experiences. Wayne Proudfoot on the Cultural Construction of Experiences. Religious Studies 48 (1): 101-117.

Cates, Diana Fritz. 1997. Choosing to Feel. Virtue, Friendship, and Compassion for Friends. Notre Dame, IN: University of Notre Dame Press.

Coakley, Sarah. 2009. Dark Contemplation and Epistemic Transformation. The Analytic Theologian Re-Meets Teresa of Avila. In Analytic Theology. New Essays in the Philosophy of Theology, 280-312 (ed. by O. Crisp \& M. Rea). Oxford: Oxford University Press.

De Cruz, Helen \& De Smedt, Johan. 2015. A Natural History of Natural Theology. The Cognitive Science of Theology and Philosophy of Religion. Cambridge, MA: MIT Press.

Draper, Paul. 2002. Seeking But Not Believing. Confessions of a Practicing Agnostic. In Divine Hiddenness. New Essays, 197-214 (ed. by D. Howard-Snyder \& P.K. Moser). Cambridge: Cambridge University Press.

Evans, C. Stephen. 1985. Philosophy of Religion. Thinking About Faith. Downers Grove, Ill., U.S.A.: InterVarsity Press.

19 I would like to thank Olli-Pekka Vaino, Aku Visala, and the other attendees of the 2016 Helsinki Analytic Theology Workshop for their helpful comments and questions on the presentation which gave rise to this paper. 
-. 2010. Natural Signs and Knowledge of God. A New Look at Theistic Arguments. Oxford: Oxford University Press.

-. 2011. Religious Experience and the Question of Whether Belief in God Requires Evidence. In Evidence and Religious Belief, 37-51 (ed. by K.J. Clark \& R.J. VanArragon). Oxford: Oxford University Press.

Farennikova, Anna. 2013. Seeing Absence. Philosophical Studies 166 (3): 429-454.

Forman, R. K. 1997. The Problem of Pure Consciousness. Oxford: Oxford University Press.

Goris, Harm. 2012. Angelic Knowledge in Aquinas and Bonaventure. In A Companion to Angels in Medieval Philosophy, 149-186 (ed. by T. Hoffmann). Leiden: Brill.

Griffioen, Amber L. 2017. Overview: Religious Experience and Divine Action. Forthcoming entry for the Digital Humanities Project on "Special Divine Action" (ed. Andrew Pinsent). https://sda.bodleian.ox.ac.uk/sda/ (site in development).

Hendry, George S. 1980. Theology of Nature. Philadelphia, PA: Westminster Press.

Hick, John. 1984. The Philosophy of World Religions. Scottish Journal of Theology 37 (2): 229-236.

-. 2006. The New Frontier of Religion and Science. Religious Experience, Neuroscience and the Transcendent. Basingstoke: Palgrave Macmillan.

James, William. 2004. The Varieties of Religious Experience. A Study in Human Nature. Introduction and Notes by Wayne Proudfoot. New York: Simon \& Schuster.

Luhrmann, Tanya M. 2012. When God Talks Back. Understanding the American Evangelical Relationship with God. New York: Vintage Books.

Mavrodes, George I. 1970. Belief in God. A Study in the Epistemology of Religion. Washington, D.C.: University Press of America.

McGrath, Alister E. 2008. The Open Secret. A New Vision for Natural Theology. Malden, MA: Blackwell.

Nasr, Seyyed Hossein. 2007. The Garden of Truth. The Vision and Promise of Sufism, Islam's Mystical Tradition. New York: HarperOne.

Otto, Rudolf. 1958. The Idea of the Holy. An Inquiry into the Non-rational Factor in the Idea of the Divine and its Relation to the Rational. Trans. by J.W. Harvey. London: Oxford University Press.

Pannenberg, Wolfhart. 1993. Toward a Theology of Nature. Essays on Science and Faith. Louisville, KY: Westminster/John Knox Press. 
Plantinga, Alvin. 1980. The Reformed Objection to Natural Theology. Proceedings of the American Catholic Philosophical Association 54: 49-62.

-. 2000. Warranted Christian Belief. New York: Oxford University Press.

Proudfoot, Wayne 1985. Religious Experience. Berkeley: University of California Press.

Rea, Michael. 2009. Narrative, Liturgy, and the Hiddenness of God. In Metaphysics and God. Essays in Honor of Eleonore Stump, 76-96 (ed. by K. Timpe). New York: Routledge.

Schleiermacher, Friedrich. 1999. The Christian Faith. Trans. by H.R. Mackintosh. London: T \& T Clark.

Smart, Ninian. 1965. Interpretation and Mystical Experience. Religious Studies 1 (1): 75-87.

Stace, Walter T. 1961. Mysticism and Philosophy. London: Macmillan.

Sudduth, Michael. 2009a. Revisiting the 'Reformed Objection' to Natural Theology. European Journal for Philosophy of Religion 2 (2): 37-62.

-. 2009b. The Contribution of Religious Experience to Dogmatic Theology. In Analytic Theology. New Essays in the Philosophy of Theology, 214-232 (ed. by O. Crisp \& M. Rea). Oxford: Oxford University Press.

Swinburne, Richard. 2004. The Existence of God. (2nd ed.). Oxford: Clarendon Press.

Taves, Ann. 2009. Religious Experience Reconsidered. A Building Block Approach to the Study of Religion and Other Special Things. Princeton: Princeton University Press.

Turner, Denys. 2005. Faith, Reason, and the Existence of God. Cambridge: Cambridge University Press.

Visser, Sandra \& Williams, Thomas. 2009. Anselm. Oxford: Oxford University Press.

Wynn, Mark. 2009. Towards a Broadening of the Concept of Religious Experience. Some Phenomenological Considerations. Religious Studies 45 (2): 147-166.

- 2012. Re-Enchanting the World. The Possibility of Materially-Mediated Religious Experience. In Theology, Aesthetics, and Culture. Responses to the Work of David Brown, 115-127 (ed. by R. MacSwain). Oxford: Oxford University Press.

-. 2013. Religious Experience and Natural Theology. In The Oxford Handbook of Natural Theology, 325-339 (ed. by R. Re Manning). Oxford: Oxford University Press.

Yadav, Sameer 2016. Mystical Experience and the Apophatic Attitude. Journal of Analytic Theology 4 (1): 17-43. 